THE PROBLEM OF ACTION AND INTEREST ALIGNMENT:

BEYOND JOB REQUIREMENTS AND INCENTIVE COMPENSATION

\author{
ALEXANDER J.S. COLVIN \\ Department of Labor Studies and Industrial Relations \\ The Pennsylvania State University \\ 124 Willard Building \\ University Park, PA 16802-2800 \\ Tel: (814) 865-0754 \\ Fax: (814) 863-3578 \\ ajc10@psu.edu \\ WENDY R. BOSWELL \\ Mays Business School \\ Department of Management \\ Texas A\&M University \\ Tel: (979) 845-4045 \\ Fax: (979) 845-9641 \\ wboswell@,tamu.edu
}




\title{
THE PROBLEM OF ACTION AND INTEREST ALIGNMENT: BEYOND JOB REQUIREMENTS AND INCENTIVE COMPENSATION
}

\author{
Abstract \\ We introduce two concepts, action alignment and interest alignment, that we propose to \\ help explain the linkages between employee behaviors and organizational strategy. We first examine \\ the problem of action alignment, developing employee ability to identify and engage in behaviors \\ that most effectively lead to the realization of the goals of organizational strategy. In particular, our \\ discussion of action alignment focuses on the issues of employee line of sight to organizational \\ strategy and the development of shared mindsets within the organization. We argue that aligned \\ actions involving employee behaviors that are discretionary and difficult to specify in advance are \\ especially important because they hold the potential for sustainable competitive advantage leading to \\ organizational value creation. Then we turn the problem of interest alignment, how to motivate \\ employees to engage in such discretionary/unspecificable aligned actions. We argue for moving \\ beyond the common emphasis on incentive compensative in achieving interest alignment and \\ explore the role of distributive issues in compensation and the role of intrinsic factors deriving from \\ the inherent value and meaningfulness of work for employees.
}




\section{Introduction}

At their most basic level, all organizations are composed of people. The employees of an organization have been recognized as a type of resource that has the potential to be rare, valuable, and inimitable, thereby providing firms with a basis for sustainable competitive advantage (Barney, 1991). The question of how to deploy an organization's human resources so as to most effectively achieve the goals of the firm has been a central focus of strategic human resource management (HRM) research. Strategic HRM research has sought to understand how the pattern of human resource management practices and activities can achieve both fit with the business strategy of the firm and flexibility in responding to changes in the organizational environment, as well as in the strategy itself (Wright \& Snell, 1998). Much of the strategic HRM research has focused on what patterns or configurations of human resource management practices most effectively realize organizational strategy and maximize performance (e.g., Arthur, 1994; Huselid, 1995). At the same time, there has been periodic recognition that it is ultimately employee behaviors, rather than the human resource practices themselves, that are the source of value creation for the organization (e.g. MacDuffie, 1995; Schuler \& Jackson, 1987; Wright \& Snell, 1998).

In this paper, we build on calls for a behavioral focus in strategic HRM research (Gratton Hope-Hailey, Stiles, \& Truss, 1999; Jackson, Schuler, \& Rivero, 1989; Wright \& Snell, 1998) by examining the problem of how to link individual employee behaviors to the overall strategic goals of the organization. We start with the problem that some of the most valuable employee behaviors are those that are discretionary and difficult to specify in advance. As organizations becoming increasingly "boundaryless” or “jobless” (Ashkenas et al., 1995; Bridges, 1995; Lawler, 1994), it becomes not only harder, but also less advantageous to narrowly prescribe employee job behaviors. Rather, discretionary employee behaviors that are difficult to specify in advance are particularly valuable to organizations because, unlike routine job performance, they are difficult for competitors 
to imitate or replicate and thus may provide a source of sustainable competitive advantage.

In order to obtain such valuable discretionary behaviors, organizations need employees to identify and be able to perform these desirable actions, what we refer to as the problem of action alignment, and also to be willing to engage in these aligned actions, what we refer to as the problem of interest alignment. As MacDuffie (1995: 199) notes, "Skilled and knowledgeable workers who are not motivated are unlikely to contribute discretionary effort. Motivated workers who lack skills or knowledge may contribute discretionary effort with little impact on performance.” However, we will argue that achieving action and interest alignment involves problems that go beyond those of assembling a workforce with the appropriate knowledge, skills and abilities (KSAs) and providing it with the right monetary incentives to motivate desired behaviors.

First, in the area of action alignment we argue for greater emphasis on employee understanding of, or "line of sight" to (Boswell, in press; Boswell \& Boudreau, 2001), the organization's strategy and on shaping employee mindsets as opposed to directing employee behavior. Emphasis on line of sight between the employee and the organization's strategy leads to a heightened importance for communication and information sharing as part of the HRM strategy. A switch from a control-based approach to managing employees to a focus on shaping employee mindsets (Mintzberg, 1987; Simon, 1991; Weick \& Roberts, 1993) as a central HRM activity has broad implications for the role of HR in the organization.

Second, in the area of interest alignment we argue for a broader conception of employee interests than the common emphasis on extrinsic rewards leading to prescriptions emphasizing incentive compensation as the primary HRM tool (Gerhart \& Milkovich, 1990). While incentive compensation is clearly a valuable mechanism for interest alignment, we argue for a greater recognition of the importance of distributive issues in compensation (Bloom, 1999; Cowherd \& Levine, 1992; Pfeffer \& Langton, 1993) in achieving interest alignment. In addition, building on 
work design (Hackman \& Oldham, 1976, 1980) and organizational behavior (Chatham, 1989;

Kristof, 1996; Schneider, 1987) theories and research, we argue for increased emphasis on the role of intrinsic motivation in achieving interest alignment between the employee and organizational strategy. We begin by reviewing existing approaches to employee-organization alignment in the HRM literature and then turn to our analysis of the problems of action and interest alignment.

\section{Employee-organization alignment in the HRM literature}

Whereas historically human resource management research developed out of a concern with functional personnel issues such as the development of valid selection tests and the design of compensation and benefits systems (Wright \& Boswell, 2002), in recent years the issue of how employees are aligned with organizational needs has become an important focus of HRM research (cf Boswell, in press; Boudreau \& Ramstad, 2003; Gratton et al. 1999; Truss, 2001). In part, this focus in HRM research has involved a shift in the outcomes of interest from individual level impacts to outcomes at the level of the organization (Becker \& Gerhart, 1996; Delery \& Shaw, 2001). However the shift has not simply been to using organizational performance measures as the dependent variables of interest, but also a growing interest in how employees relate to the organization and how human resources contribute to the business strategy of the organization. Driving much of this interest is the underlying idea that human resource management can play a more central role in organizational success by enhancing the contribution of employees to organizational value creation (Wright \& McMahan, 1992).

Although there is relatively widespread support in recent research for the idea that human resources can and should play a key role in creating organizational value (e.g., Batt, 2002; Boswell, in press; Delery \& Shaw, 2001; Lepak \& Snell, 2002), there is much greater diversity in views on how employees and HRM practices can contribute to organizational value. Attempts to address the issue 
of how to align employees and organizational needs have emerged from both micro (individual level) and macro (organizational level) HRM research perspectives.

The micro and macro HRM perspectives have generally evolved as distinct areas of research (Wright \& Boswell, 2002). The former has a foundation in industrial/organizational psychology and focuses on the effects of single HRM practices or work policies on individual-level (or team/grouplevel) outcomes such as work attitudes, behaviors, and performance. The latter has linked the HRM literature to research on business strategy and focuses on the effects of sets of HRM practices and HRM strategies on organizational-level outcomes. Each of these perspectives has attempted to address the problem of alignment, each with its own limitations. As argued by Wright and Boswell (2002), an integration of the micro and macro HRM perspectives is needed to more fully understand how HRM adds value to an organization. Accordingly, the present research will seek to address the key question of how employees contribute to value creation at the organizational level, thereby providing greater integration between the micro and macro HRM perspectives.

From a micro perspective, the literature on person-organization (P-O) fit is concerned with aligning employee (or job applicant) personalities, values, needs, or skills, with the organization's culture, opportunities, or requirements (e.g., Bretz \& Judge, 1994; Kristof, 1996; Kristof-Brown, Zimmerman, \& Johnson, 2005). The focus here is on individual and organizational characteristics rather than on organizational strategy, but nevertheless suggests the important role of congruence to effective organizational functioning. The major limitation of the micro HRM perspective on alignment is that the research focuses on individual-level outcomes such as work attitudes and job or task performance.

By contrast, the main limitation of the SHRM approach from a micro HRM perspective is that this literature has generally focused on HRM practices to the neglect of what such practices do at the level of individual employees (cf Arthur, 1994; Huselid, 1995). HRM practices help determine 
employee behavior, but ultimately, it is the employee actions that matter. The need for a behavioral perspective that moves beyond just HRM practices has been recognized in some of the SHRM literature. For example, Schuler and Jackson (1987) argued that organizations strive to induce certain behaviors (e.g., creativity) dependent on the firm's competitive strategy (e.g., innovative) through HRM practices (e.g., rewarding experimentation). Wright and Snell (1998) proposed that expanding the breadth of employee behavior repertoires is one of the key ways in which HRM can enhance organizational flexibility. However, much of the current SHRM literature continues to focus on the configuration of HRM practices (e.g., high commitment work practices), rather than on employee behaviors, as the source of potential strategic advantage. By contrast, in our view, adopting a perspective that focuses on the role of employee behaviors in contributing to organizational strategy holds the potential of bridging the micro and macro HRM perspectives on alignment by linking together HRM practices, employee actions, and organizational outcomes.

\section{Action alignment}

\subsection{The concept of action alignment}

We begin with the issue of alignment between employee actions and an organization's strategic goals. The question here is how do employees contribute to the success of the organization's strategy? As noted, extant SHRM research often argues for the importance of alignment between HRM practices and firm strategy for realization of the organization's strategic goals (Arthur, 1992, 1994). Yet, having a HRM practice in place has no direct effect on the realization of organizational strategy. It is ultimately the actions put forth by the actual human resources (i.e., the employees) that produce desired outcomes (Boudreau \& Ramstad, 2003; Wright \& Snell, 1991). That is, realization of an organization's strategic objectives is through individuals and their behavior (Boswell, in press; Gratton, et al., 1999; Jackson, Schuler, \& Rivero, 1989). We conceptualize aligned actions as those 
actions consistent with an organization's strategic goals. More formally defined, action alignment is the alignment of employee actions with the objectives of an organization's strategy. Through employee behaviors that are aligned actions, organizations are able to enhance execution of their business strategies and thereby increase the employee contribution to organizational value creation.

Action alignment focuses on employee contributions to an organization's strategic objectives not just on individual job performance. The potential for value creation for the organization stems from those discretionary and unspecifiable employee actions that contribute to the execution of those objectives. Thus aligned actions are generally not part of routine employee behavior as specifically defined by a formal job description. Routine employee behavior is specifiable and as such does not hold the potential for above average value creation. This is consistent with the notion of sustainable competitive advantage (Barney, 1991) in that routine job behaviors are likely to reap only average returns given that they are readily imitated. Action alignment is, therefore, not only what an employee does but also how. As an example, customer satisfaction and retention is an important strategic objective for many organizations, yet action alignment may be reflected in recognition by employees of who are the most valuable customers to the firm or serving customers most profitably given the firm's product mix and overhead. Thus while firm strategy is routinely defined (though evolves and may change), what employees should do to further this strategy may not be amenable to specification in advance or monitoring. This suggests choice on the part of employees or, perhaps more aptly, a decision-making premise or mindset to fostering aligned actions.

The idea that aligned actions are not generally part of routine job performance is similar to discussions of organizations as virtually "boundaryless" or “jobless" (Ashkenas et al., 1995; Bridges, 1995; Lawler, 1994; Nelson, 1997), recognizing the importance of minimizing structure so that people and their ideas and information are available where most needed. This entails a paradigmatic shift from employees performing well-defined job duties to employees understanding the "big 
picture" and contributing to the attainment of firm goals. By acknowledging that management cannot foresee every situation, employees make judgments and use discretion to "do the right thing" guided by the company's corporate strategy. Action alignment thus goes beyond simply effective job performance, holding the potential for value creation if it can be achieved by an organization.

This discussion is consistent with prior work (e.g., Mintzberg, 1987; Simon, 1991; Weick and Roberts, 1993) that has emphasized shaping employee mindsets (or "collective minds") rather than prescribing behaviors to foster those decision-making premises that are in line with an organization's goals. Herbert Simon (1991) observed, "Doing the job well is not mainly a matter of responding to commands, but is much more a matter of taking initiative to advance organizational objectives...For the organization to work well, it is not enough for employees to accept commands literally... What is required is that employees take initiative and apply all their skill and knowledge to advance the achievement of the organization's objectives" (p. 32). Simon further discussed the importance of shaping a mindset rather than simply directing employee behaviors because it is difficult to know in advance what behavior will best contribute to the realization of the firm's objectives.

Recent research on the concept of employee line of sight is relevant to this issue. Boswell (in press) and Boswell and Boudreau (2001) defined line of sight as employee understanding of an organization's strategic objectives and how to contribute to those objectives. The latter component of this conceptualization, as well as the operationalization of the construct, links to the notion of aligned actions. More specifically, employee understanding of how to contribute to a firm's strategic objectives (i.e., understanding of aligned actions, Boswell, in press) is important to directing effort toward those objectives. The idea is that translating strategic goals into an enacted strategy requires development of a "line of sight" amongst employees about what the strategy involves and how to contribute. The line of sight construct focuses on an employee's cognitive awareness of "important" (and unimportant) behaviors at the particular organization rather than behavioral outputs. We see 
employee knowledge as an important determinant of behavior (and will elaborate on this more later), yet employee awareness of strategic goals by itself is not enough to produce value creation. Employees may know what to do (e.g., share information with coworkers) but not have the opportunity (e.g., overloaded with other work tasks) or motivation (e.g., rewarded for individual not group performance). It is the actual actions that contribute to an organization's attainment of its strategic goals and create value. To achieve action alignment it is necessary to have both a shared mindset between employees and the organization and the resulting behavioral outputs from employees leading to attainment of the strategic goals of the organization.

The importance of having awareness of, or shared mindset toward, the strategic objectives of the firm can be illustrated by considering a job not generally thought of as having high strategic value. The tasks of a janitor, for example, on the surface appear to be quite well-defined and not particular value-laden (e.g., empty trash, clean washrooms). However, a janitor with a clear understanding of the organization's goals would likely have a different mindset about and approach to his/her job focusing not simply on keeping things clean and debris free but instead on how to do so in a way that would best serve the company. This may involve the timing or ordering of performing certain tasks (e.g., ensuring the most frequented restrooms are clean for client use) as well as engaging in behaviors not traditionally considered as part of the janitorial job (e.g., pointing about machine malfunctions, assisting customers). This example illustrates not only the importance of aligned actions to value creation but also that such alignment can (and arguably, should) occur at all levels of the organization. Our point is not that all employees will have equal opportunity to engage in aligned actions. We recognize that there will be core employees whose contribution of aligned actions will be particularly critical for organizational success (Lepak \& Snell, 1999; Lepak \& Snell, 2002). However if organizations focus only on the potential contributions of core employees as a source of value creation, they may miss opportunities for competitive advantage available from 
harnessing the potential of their entire workforce.

\subsection{Factors producing action alignment}

What are the determinants of action alignment? Behavior can be thought of as a function of capability, opportunity, and motivation (Bailey, 1993). Thus whether an employee behaves in alignment with the strategic goals of the organization depends on he/she having traits, skills and abilities compatible with the needs of the organization, whether he/she has the occasion and opportunity to behave accordingly, and whether he/she has the incentive to do so. The basic idea that HRM practices affect behavioral outcomes by influencing employee capability, opportunity, and motivation has received increasing recognition in the HRM literature (Bailey, 1993; Boudreau \& Ramstad, 2003; Delaney \& Huselid, 1996). We will follow this approach in exploring the determinants of action alignment. We first discuss the role of capability and opportunity as providing the elements needed to obtain aligned actions. In the following section, we will then turn to discussing the determinants of interest alignment, which links the outcomes of aligned actions back to employees, providing the motivation for employees to engage in aligned action.

Individual capability is an important component to understanding behavior (e.g., Dunnette, 1973). It is generally assumed that employee capability (i.e., knowledge, skills, abilities, traits, values, attitudes) should be closely aligned with job requirements. Yet research has also recognized that employee capability should be consistent with organizational goals to be maximally effective (e.g., Tichy, Fombrun, \& Devanna, 1982; Wright, Smart, \& McMahan, 1995). The general argument is that organizational strategies require specific individual capability. For example, Olian and Rynes (1984) proposed a strategic staffing model based on Miles and Snow's (1978) typology of strategic types. They argued that selection criteria should vary depending on an organization's strategy. For example, effective defender organizations will select individuals with finance or production backgrounds while effective prospector organizations will select individuals with general research 
skills or marketing abilities.

Empirical research has begun to investigate the capability-strategy link through a contingency lens. For example, Wright et al. (1995) found evidence that NCAA basketball team performance was higher when player skills (e.g., endurance) were aligned with team strategy (e.g., speed strategy). Similarly, Gupta and Govindarajan (1984) showed that congruence between managerial characteristics (e.g., tolerance for ambiguity) and business strategy (e.g., build strategy) enhanced organizational effectiveness.

Thus a first factor determining whether or not employees can engage in aligned actions is possession of the requisite capability. Our purpose here is not to lay out specific employee capabilities consistent with various business strategies. Rather we generally propose that employee capability is necessary but insufficient to foster action alignment and, ultimately, strategic value. This has important implications for HRM practices in creating organizational value. Specifically, we argue that HRM practices first create value to the extent that they promote employee capability aligned with the strategic goals of an organization. Presumably aligned capability could be either selected for ("bought") or developed (“made"; Kerr \& Jackofsky, 1989). Thus HRM practices such as valid selection methods, performance feedback, and investment in training can be effective in realizing a range of different business strategies. This is supported by the main effect found for such work practices regardless of a firm's business strategy (e.g., Huselid, 1995), consistent with the universalistic perspective on the contribution of HRM practices to the organization. Yet the notion of alignment suggests such practices should be focused on selecting for or developing those capabilities of particular relevance to an organization's strategic goals. For example, while valid selection methods are universally important across organizations, strategic value is created to the extent that the KSAs acquired are consistent with the particular strategic objectives of the organization. Similarly, performance feedback and employee development should direct employee 
actions and outputs congruent with the organization's strategic goals and not simply effective performance of tasks specific to a particular job. In this respect, the universalistic and contingent perspectives can be bridged by recognizing elements of validity in both perspectives: high performance work systems are universally effective across different organizations because they create the capability for a range of aligned actions by employees, where the specific behaviors engaged in are contingent on the particular strategic goals of the organization.

However, the above suggests a fairly control-based approach to achieving action alignment. That is, an organization defines then selects for or develops the requisite employee capability consistent with its business strategy. This assumes such capability is readily apparent. Yet fit can be thought of more broadly than the congruence between firm strategy and employee capabilities. More generally, the notion of employee fit with the organization also encompasses employee values and personality (Kristof-Brown et al., 2005). Although the dynamic business environment suggests the difficulty firms may have in specifying actions, and that regardless we argue firm value is derived from more discretionary employee behavior, employees that are aligned with the values and goals of the organization are likely better able and motivated to engage in those actions of importance to the firm. Indeed, George (1992) proposed that the implicit assumption behind desiring individuals to "fit" is that they will behave in a way congruent with the organization's goals, and Schneider's (1987) argument that organizational members determine the goals of the organization (i.e., "the people make the place") suggests that individuals who fit with the current organizational constituents will further reinforce the extant goals and strategic direction of the firm. As noted by Schneider, this status quo may actually be deleterious to organizational change; however, this does not negate the important role of "fit" in promoting those actions congruent with the organization's strategic intent. Aligned actions are not simply a function of requisite capability; an individual must have the opportunity to apply his/her capabilities. This is related to the notion of situational constraints 
whereby an individual may have the capability to perform a task but is in some way constrained into inaction. For example, research by O’Connor and colleagues (e.g., O’Connor et al., 1984; Peters, O’Connor, \& Rudolf, 1980) has shown that situational constraints, such as lack of job-related information, inadequate equipment, insufficient support from others, and lack of authority, associate negatively with performance outcomes, as well as work attitudes and retention. As noted by Peters and O’Connor (1980), “in many situations, persons who are both willing and able to successfully accomplish a task may be either inhibited in or prevented from doing so" (p. 391).

What creates such opportunity for aligned actions? Management practices focused on prescribing job tasks and behaviors are not likely to be effective at fostering the more discretionary and unspecifiable actions that contribute to the strategic goals and value creation discussed in this paper. Rather, we suggest an important role for creating a shared mindset (as discussed above) between employees and the organization, and specifically employee awareness of (or line of sight toward; Boswell, in press) an organization's goals. Such understanding should make it more possible that employee actions will align with the firm's interests and needs. Conversely, if employees lack information on organizational objectives and expectations for contributing to these objectives, there is arguably a greater risk of ineffective or inappropriate behaviors. For example, if a firm fails to communicate to its employees who are the company's most important customers, this could lead to missed opportunities to provide these clients with the highest level of service.

Effective communication of the organization's objectives is imperative for employees to understand and act on the firm's strategic objectives. For example, research by Cohen, Mohrman, and Mohrman (1999) on knowledge teams found a positive relation between a clearly defined organizational strategy and team members' shared understanding of that strategy. The researchers stressed the importance of clearly articulating strategic priorities to employees in order to promote understanding and ultimately performance. In their discussion of how firms can assess their 
“dominant logic," Lengnick-Hall and Wolff (1998) proposed that clear articulation of the organization's strategy is not only useful in determining if the company's strategic orientation is appropriate, but communication also helps uncover and resolve contradictory behaviors across the firm. Consistency in direction then becomes more feasible.

The issue of employee involvement in decisions related to their job is also relevant to creating opportunity for aligned actions. Employee involvement is based on the notion that those doing the work (i.e., the employees) are in the best position to provide suggestions and make decisions (Ichniowski et al., 1996). Employee involvement practices range from problem-solving groups to more extensive participation through self-directed work teams (Appelbaum \& Batt, 1994). It has also been suggested that differences between individual and organizational needs or goals can be reconciled via participation (e.g., Latham \& Yukl, 1975). Thus greater involvement in decisions related to their job should promote action alignment by helping to connect employees with the broader functioning of the organization and helping to reconcile inconsistency.

Similarly, a shift from employees performing narrowly-defined job duties to broadened job roles and greater job decision latitude (Karasek, 1989) can afford employees opportunity for action alignment by creating the expectation that employees contribute as needed to the attainment of firm goals (Lawler, 1994; Nelson, 1997). Indeed, creating organizational value implies employee contributions have the potential to go beyond that derived from a traditional job analysis approach (McCormick, 1976). Providing employees with the opportunity to act in this way is imperative.

\section{The challenge of interest alignment}

\subsection{The concept of interest alignment}

As discussed earlier, aligned actions hold the potential for creating competitive advantage and value for organizations because they are discretionary and unspecifiable in nature. Yet these 
same characteristics make aligned actions particularly subject to the willingness of employees to engage in them. If employees are to be motivated to engage in aligned actions that are discretionary and cannot be specified by management, utilizing their own initiative to discover and define new work behaviors for themselves, then it will be critical that the employees view their own interests as being aligned with those of the organization. In this section, we examine the extrinsic and intrinsic factors contributing to interest alignment.

We define interest alignment as the alignment of the interests of employees with the organization, its strategy, and goals. We use the term interests broadly to refer to the set of extrinsic and intrinsic benefits that employees derive from their work and employment. Extrinsic benefits for employees most directly consist of the compensation they are paid for their work, but also include benefits such as employment security and opportunities for career advancement. Whereas extrinsic benefits, such as compensation, are often seen as the primary employee interest in employment, some research has also emphasized the intrinsic value of meaningful work (Hackman \& Oldham, 1976, 1980). In Hackman and Oldham's (1976) theory of job design, the idea of the value of meaningful work was focused on the level of the individual job. In contrast, we shift the focus to the organizational level and argue that the employee interest in the intrinsic value of work also includes the employee's belief in the organization's strategy and the outcomes it is seeking to achieve. Interest alignment thus consists of the combination of both extrinsic and intrinsic benefits that employees derive from the realization of organizational strategy.

\subsection{Extrinsic factors in interest alignment}

As the primary extrinsic benefit that employees receive in return for their work, compensation is the natural starting point for thinking about the alignment of employee interests with organizational strategy. From the perspective of interest alignment, the operative question for employees can be posed as follows: If the organization succeeds in its strategy, will I, as an 
employee, benefit in my compensation? There are two major alternative ways compensation systems can address the problem of aligning employee interests with organizational strategy. The first is the development of incentive compensation systems that attempt to align employee interests with that of the organization by making compensation contingent on particular outcomes or behaviors. The second is the distributional aspect of compensation, which addresses the question of how the proceeds of the enterprise are distributed across different groups of employees and other organizational stakeholders. We will address each of these issues in turn.

\subsubsection{Incentive compensation.}

The development of incentive compensation systems rests on the two theoretical pillars of expectancy theory and agency theory. Each of these perspectives provides a strong theoretical basis for the use of incentive compensation systems by organizations to obtain desired behaviors.

Expectancy theory predicts that motivation is enhanced when behaviors are highly instrumental in achieving desired outcomes. For compensation systems, this suggests that making pay contingent on outcomes that result from desired behaviors will enhance the motivation of employees to engage in these behaviors (Gerhart \& Milkovich, 1990). Agency theory approaches similar questions from the perspective of addressing conflicts of interest between the organization and the employee, or in terms of agency theory, the principal and the agent (Jensen \& Meckling, 1976). Agency theory starts with the essential problem of employment that a principal is delegating work to an agent who actually performs the work in return for some compensation. It proceeds from the rather dour and pessimistic assumption that the agent as a self-interested rationalist will take advantage of the inability of the principal to monitor all aspects of the agent's behavior by shirking from the contracted obligations where possible. In order to avoid the problem of shirking, the principal needs to either invest in monitoring behavior or create a contract that rewards the agent based on outcomes (Eisenhardt, 1989). Given that monitoring is often costly and increasingly 
difficult for jobs that involve a high degree of uncertainty and discretionary behavior, the agency theory perspective has led to strong support for the extensive use of incentive compensation systems tied to performance outcomes (Gerhart \& Milkovich, 1990). Expectancy theory would similarly suggest that in order to foster behaviors that contribute to organizational strategy, employees should have an expectation of receiving rewards tied to the organizational level outcomes of executing this strategy. This suggests that to foster interest alignment, compensation should be made contingent on organizational-level outcomes, such as through profit sharing or plant or divisional performance bonuses.

Although clear in theory, this prescription can be difficult to follow in practice. Where the relationship between desired behaviors and outcomes is relatively direct, incentive compensation systems can be more easily designed that follow the prescriptions of expectancy or agency theory. For example, in a customer sales setting incentive compensation can make a direct connection between desired behaviors and outcomes by making pay contingent on the number or value of sales achieved by the employee. By contrast, where the objective is to align employee behaviors with a more general objective of organizational strategy, it can be much more difficult to create a link. For example, if an organization's strategy is focused on developing a reputation of being the leading brand in terms of quality for a particular market niche, it may be very difficult to link any individual employee's behavior to this strategic outcome. In terms of expectancy theory, the lack of instrumentality of employee behavior in achieving the desired outcome will reduce employee motivation to engage in this behavior (Vroom, 1964). One remedy for this problem is to attempt to specify more particular behaviors and lower-level outcomes in the incentive compensation system (e.g., rewarding a marketing manager for achieving a certain number of mentions of the brand in a local media market). The problem with this remedy is that it assumes that the employee behaviors can be specified in advanced. Yet a central point of the action alignment analysis is that there are 
discretionary employee behaviors that may not be easily specified that nonetheless substantially contribute to the realization of organizational strategy.

\subsubsection{Distributional aspects of compensation.}

Another approach to understanding the compensation-performance relation has looked to more egalitarian pay distribution systems as a way to enhance organizational performance. In contrast to the assumption underlying agency theory of self-interest as the basic motivation of employees, these distributional arguments have built on the idea of a broader set of employee motivations deriving from common interests with other employees. Bloom (1999) has described the argument in the following terms: “... compressed pay distributions can be beneficial for group performance because they may inculcate feelings of fairness and common purpose, foster cooperative, team-oriented behavior, and support common goal orientations" (p. 26). In contrast to perspectives such as tournament theory (Ehrenberg \& Bognanno, 1990) suggesting unequal pay distributions should be used to encourage employees to compete against each other to see who can perform the best, the rationale for lower pay dispersion builds on the premise that employees in an organization are engaged in a collaborative endeavor. High pay dispersion may suggest that those at the top of the distribution will garner all the rewards if the organization is successful, whereas lower pay dispersions suggests to employees that if they succeed as an organization the proverbial "rising tide will lift all boats."

A series of studies have found beneficial effects for lower pay dispersion. A study of university faculty members found that high wage dispersion had negative effects on job satisfaction, productivity, and collaborative behavior (Pfeffer \& Langton, 1993). Lower pay dispersion in professional baseball teams was found to be associated with better individual and team performance (Bloom, 1999), and higher pay dispersion among managers associated with lower tenure and greater turnover (Bloom \& Michel, 2002). Similarly, lower pay inequality between workers and top-level 
managers was found to be associated with higher product quality (Cowherd \& Levine, 1992). This last finding can be linked to research indicating that pay differences between managers and workers are lower in organizations adopting high performance work systems (Colvin, Batt, \& Katz, 2001). Lower pay differences between managers and workers are argued to be particularly important for HPWSs because they help foster group cohesiveness and reinforce the employee involvement that are key goals of these work systems.

Underlying the arguments for performance effects of lower pay dispersion is the idea that the experience of and belief in shared fates will have positive motivational effects on the behavior of employees within a group or organization. Linking employees together in how the proceeds of organizational success are distributed in terms of compensation will likely increase the willingness of employees to engage in behaviors that result in collective benefit to the organization and their fellow employees. We propose that the pay dispersion argument about the distribution of rewards among employees can be extended to the problem of obtaining interest alignment between the employee and the organization. To the degree that employees believe that both they and the organization are linked in sharing the benefits of successful realization of the organization's strategy, a principle or ethos of common benefit from collective achievement will be established. While performance-based pay could be a mechanism for sharing these benefits, an organization could equally well establish an ethos of shared benefit by following a principle of rewarding employees with regular wage or salary increases so long as the organization is able.

Two corollaries follow from this idea. The first is that violations of existing patterns of distributional equity will reduce employee perceptions of interest alignment. For example, if during a downturn employees are expected to endure wage or salary cuts, but other important stakeholders do not share in these losses, then interest alignment will be sharply reduced. By contrast, establishing principles of shared benefit and loss, such as when CEO's or other executives take salary cuts equal 
to or greater than those of lower level employees, interest alignment can be maintained even in a context of reduced economic rewards. The second corollary is that employees will be sensitive to large disparities between the organization and themselves. So, even if they are being paid comparable to the relevant labor market, employees may still perceive a lack of interest alignment if they do not see themselves sharing in the successes of a particularly wealthy organization. An example of this phenomenon can be seen in the campaigns for improved compensation launched by cleaning, maintenance and clerical staff at some major private universities, which have focused on the large endowments of these relatively wealthy organizations as a justification for higher compensation levels for their employees (Hoerr, 2001). Whereas the first corollary relates to the principled of shared losses, the second corollary relates to the principle of shared benefit.

So far our discussion of interest alignment has focused on issues relating to traditional monetary compensation. Although monetary or financial compensation continues to be the primary focus of compensation research, recognition has grown of the need to look beyond monetary compensation to understand what motivates employee behavior (Rousseau \& Ho, 2000). The concept of total compensation has been used to encompass both monetary rewards, such as base pay, incentive pay, and benefits, and nonmonetary rewards, such as recognition, learning, and quality of work-life (e.g., Milkovich \& Bloom, 1998; O’Neal, 1998). In the subsequent sections, we build on the idea of total compensation to look beyond traditional monetary compensation in understanding how employee interests are aligned more broadly with the outcomes of organizational strategy.

\subsection{Intrinsic factors in interest alignment}

A growing body of research from a number of different perspectives suggests the need to broaden the definition of the value that employees derive from work and employment to go beyond the instrumental value that is the predominant focus of agency theory.

One alternative perspective on alignment between the employee and the organization is 
found in the literature on person-organization fit that has examined alignment between employee and organizational values (e.g., Chatman, 1989). As noted above, this literature suggests that rather than focusing just on monetary and other extrinsic rewards, employees are attracted to an organization and motivated to contribute to its success when there is congruence between their personal values and those of the organization (Kristof, 1996). A similar perspective suggesting a source of alignment between the organization and the employee is the Attraction-Selection-Attrition Model advanced by Schneider (Schneider, 1987; Schneider, Goldstein, \& Smith, 1995), which proposes that organizational values and goals are constructed by the personalities of the employees who are members of the organization. Employees are more likely to be attracted to and stay with organizations whose personalities (e.g., creative, egalitarian) are similar to their own.

Social identity theory provides insight on the link between the employee and the organization. This literature has argued that employees derive part of their social identity from the image of the organizations with which they are employed (Dukerich, Golden, \& Shortell, 2002). To the degree that employees perceive that the organization has an image that reflects positively on their own social identity, they will make greater efforts to contribute to the organization's success. For example, Dukerich et al. (2002) found evidence that physicians were more willing to engage in cooperative behaviors where they perceived a more positive identification with the image of the health care systems with which they were associated.

The importance of the intrinsic value of work was given prominent recognition in the job design theory of Hackman and Oldham $(1976,1980)$ who argued experienced meaningfulness of work is a critical psychological state determining personal and work outcomes. In Hackman and Oldham's theory, experienced meaningfulness of work was seen as deriving from job design features such as skill variety, task identity, and task significance. Although their theory focused on the design of individual jobs, the idea that employees derive meaning from the intrinsic value of work also has 
implications for how we think about alignment between the employee and the organization.

The common thread running through these theoretical perspectives is that they assume employees have interests in work that go beyond monetary compensation and other instrumental rewards received from employment. Whereas the agency theory perspective has emphasized extrinsic rewards of employment as the key tool in aligning the interests of the employee and the organization, these other perspectives suggest a broader notion of what constitutes the employee's interests at work, encompassing both the instrumental value that the employee derives from employment and the intrinsic value to the employee of the product of work activities. Taking this broader perspective of employee interests then has implications for how to address the problem of employee alignment. If employees believe that part of the value of their work lies in their contribution to what the organization is producing, then to the degree that the employees believe in the intrinsic value of these outcomes, they will perceive their own interests as being aligned with those of the organization.

Based on the above analysis we propose that the intrinsic value to employees of the outcomes realized through execution of organizational strategy is a key element in interest alignment for employees. In particular, we argue that employees may experience interest alignment with the organization's strategy, whether or not the outcomes from executing this strategy result in any extrinsic benefit to the employees personally, so long as they view the outcomes from the strategy as intrinsically valuable. Our understanding of employee-organization alignment needs to reflect both extrinsic and intrinsic aspects of how work creates value for employees. To the degree that the employee believes in the worth of what the organization is doing, they will perceive greater value in their own work activities and be more likely to engage in desirable aligned actions. Put alternatively, interest alignment can result from an employee belief in shared purposes with the organization they work for, rather just from the expectation of shared rewards from organizational success. 
What might this intrinsic type of interest alignment look like in practice? One example that provides a simple illustration of the role of intrinsic value in interest alignment is the profession of fire fighting. In major American cities, fire fighters are typically employees of the municipal fire department and receive regular compensation for their work. By contrast, in many smaller communities and rural areas, fire fighting is an activity undertaken by organizations of volunteer fire fighters. These volunteer fire fighters receive no direct compensation for their work, yet throughout the country fire fighting organizations are successfully staffed by volunteers. Although volunteer fire fighters clearly derive value from the social companionship of these organizations, it is difficult to understand the success of these organizations in attracting volunteer workers without taking account of the intrinsic value of the work performed by these organizations and the belief of the volunteers in this work. Turning back to the professional fire fighters of larger communities, it is clear that they derive additional extrinsic value from the compensation they receive for their work. Yet it is also implausible to believe that they do not derive the same type of intrinsic value from the services provided by their organizations.

Although fire fighters may provide an especially strong example of the intrinsic value of work, two contrasting hypothetical examples from the health care industry may help further illustrate the role of intrinsic value in interest alignment. In the first example, suppose we have an employee who is a researcher at a pharmaceutical company. Suppose the company's strategy is to strongly emphasize innovation in developing entirely new lines of drugs that will pay off over the longer term. If the employee identifies with the intrinsic value of innovative research in producing new drugs that will ultimately benefit society, the employee will have a high degree of interest alignment with the organization's goals and be especially likely to undertake aligned actions leading to the success of this strategy. There would be an increased likelihood that the researcher would go above and beyond the ordinary duties of her job to further the innovative research the organization 
is seeking. By contrast in the second example, consider a doctor working for a health organization that has a strategic goal of emphasizing the control of health care costs. If the doctor believes in the intrinsic value of delivering the highest quality of health care regardless of cost, she is likely to perceive a lower degree of interest alignment with the organization's goals. While the doctor could be given monetary incentives to cut costs, it is likely that the lack of belief in the intrinsic value of the organization's goals will reduce the extent or enthusiasm with which the doctor undertakes aligned actions directed at coming up with new ways to reduce costs.

\subsection{Linking interest and action alignment}

Why is interest alignment critical for organizations? The distributive and intrinsic factors that we have emphasized here may be important for employee perceptions of interest alignment, but a skeptic might argue that for the organization it is sufficient if compensation based incentives lead employees to perform their jobs as directed. In our argument, it is the discretionary, unspecifiable nature of critical aligned actions that make broader interest alignment so important and potentially valuable to organizations. A central dilemma in research on strategic HRM is how human resource practices can provide a source of sustainable competitive advantage (Barney, 1991) resulting in value creation for the organization, when such practices or configurations of practices can be imitated by competitors. By contrast, shifting the focus to employee behaviors, we argue that the discretionary, unspecifiable nature of aligned actions do provide such a source of sustainable competitive advantage because they are much harder to imitate. The broadly based and deeply rooted interest alignment we have described is important because it provides the critical motivation for employees to engage in these aligned actions. Developing a mutually reinforcing combination of interest and action alignment may not be easy for organizations to achieve, but once in place can provide the route by which an organization's human resources become its source of competitive advantage. 


\section{Limitations and challenges to action and interest alignment}

Our discussion has focused on the positive results from achieving action and interest alignment. However, it is important to recognize that there may be downsides to alignment as well. One clear danger to alignment is that if the organization has adopted the wrong strategy, enhancing the degree to which employees contribute to realization of this strategy is unlikely to produce positive outcomes. If alignment is particularly strong there may be dangers of groupthink (Janis, 1982) where members of the organization are so united in their perspective that they lose the ability to recognize and identify the dangers of a misdirected organizational strategy. A related problem may arise if the organization needs to alter its strategy in response to environmental or other changes (Dyer \& Shafer, 1998). Excessive alignment towards a particular strategy may inhibit the ability of the organization to adapt to a new strategic imperative. On the other hand, it is also plausible that interest alignment could enhance the willingness of employees to engage in new types of aligned actions, thereby increasing the ability of the organization to respond to change. Whether action and interest alignment enhances or diminishes the ability of organizations to respond to changing circumstances is in our view an especially critical question for future research since it goes directly to the issue of how action and interest alignment contribute to the sustainability of new value creation in a context of rapidly changing organizational environments.

A second danger is that action and interest alignment may only be established with part of the workforce. The result may be to establish an insider/outsider dynamic, in which employees who are "insiders" feel that their interests are in alignment with the organization and engage in valuable aligned actions, but that employees who are "outsiders" do not experience interest alignment or engage in aligned actions. Some organizations may believe that they can identify core employees for whom alignment is important and relegate other employees to the outsider category for whom action and interest alignment is unnecessary. This could have negative implications for the 
employment conditions of those who are not in the core group as well as reduce the potential for obtaining value creation from across the workforce. As one example, firms often limit temporary workers' access to information that may compromise a firm's competitive advantage (Matusik \& Hill, 1998), and research has shown that compared to traditional employees, contingent workers have fewer beliefs regarding reciprocal exchange with a firm (Van Dyne \& Ang, 1998). Feelings of being disadvantaged in terms of job security and rewards, which is associated with contingent work (Beard \& Edwards, 1995), has been shown to relate to reduced commitment to managerial goals, effort, and cooperation (O’Reilly \& Chatman, 1986). Feldman, Doerpinghaus, and Turnley (1994) found that temporary workers often feel they are treated impersonally, like an outsider. The same may hold for part-time work, as prior research shows part-time workers report organizational and interpersonal exclusion, often indicating they are made to feel like second-class citizens (Barker, 1995). Given firms are relying more on more on contingent labor as well as non-traditional employment arrangements (Cappelli, 1999), lack of alignment with important firm goals amongst these individuals can be problematic. If in fact there is the potential for a strategically valuable element to all jobs in an organization, then organizations that achieve action and interest alignment with their entire workforce will be better placed to capture this potential value.

It is also important to recognize that achieving action and interest alignment is not a cost and effort free endeavor for organizations. Some costs are direct, for example the need to invest sufficiently in employee compensation and benefits to achieve extrinsic interest alignment. Indirect costs can include the need to implement a less directive supervisory style in order to foster discretionary decision-making by employees. It may initially appear faster, cheaper and easier for many workplace tasks for supervisors simply to direct employees what to do. However, if supervisors are overly directive, the opportunity for the employees themselves to choose and engage in aligned actions will be lost. In order to obtain value creating aligned actions over the longer term, 
it may be necessary for the organization to bear some initial costs. Institutional constraints may be an additional barrier to development of action and interest alignment. Interest alignment assumes a sharing of the benefits of organizational success, which may not seem compatible with imperatives to maximize the returns for any particular group of stakeholders such as shareholders or creditors. Further, if organizations are trapped in a short-term cycle of decision-making, they may be unable to make the necessary sustained commitment needed to achieve alignment that will produce greater value creation in the longer term.

\section{Conclusion}

In this paper, we have discussed how employees contribute to the success of the organization's strategy and ultimately create value, thus seeking to bridge micro and macro HRM perspectives. Our argument is rooted in employee behaviors, but connects these behaviors with organizational strategy and its outcomes through the concepts of action and interest alignment. In this respect, it is an explicitly multi-level model linking individual and organizational levels of analysis (Klein, Tosi, \& Cannella, 1999). A central concern of strategic HRM research has been to focus attention on how human resources can contribute to enhancing value at the organizational level. Although we support this increased attention to organizational outcomes in the SHRM literature, in our view the key to understanding the contribution of human resources to firm value lies in linking individual level behaviors with organizational level strategies and outcomes.

A central feature of our argument is that value creation is derived from discretionary and unspecifiable employee actions; that is, actions that need to be identified and executed by the employee. Aligned actions are thus less likely to come from behavioral control systems, but rather by fostering a mindset such that employees understand and ultimately choose those behaviors that 
contribute to the execution of the organization's strategic goals. Interest alignment between employees and the organization is then critical to fostering the mindsets that lead to aligned actions.

An important feature of our argument is that the concept of interest alignment incorporates not just interests of the employee in receiving extrinsic benefits such as compensation and employment security, but also intrinsic interests deriving from the inherent value of the work. In this respect, we are taking a view of employee behavior that differs from perspectives that emphasize a more narrow set of employee motivations focused only on personal self-interest and extrinsic rewards received, exemplified by many agency theory based perspectives. This is not to deny the importance of the alignment of instrumental rewards, such as through performance-based compensation, which we view as an important component of interest alignment. Rather our argument is that a more complete understanding of employee behavior is obtained when we recognize that employees also contribute to the achievement of organizational objectives out of the employees' support for and belief in what the organization is trying to achieve. Such an approach helps provide an answer to the problem of collective action, which posits that individuals will not act in the collective interest unless they derive some specific personal reward from their actions or under some type of coercion. Given that people are by their nature organizational creatures, tending to act as groups, if they view what the organization is doing through its strategy as something they support, they are more likely to engage in discretionary actions aligned with that objective. In this sense, employees act not just as responders to organizational policies designed to influence their behavior, but as participants in the organizational enterprise. It is our view that future research on how organizations attain strategic success and create value will better understand this process if it proceeds from a recognition that employees can act as participants in value creation motivated to a significant degree by the intrinsic value of what is being achieved. 


\section{References}

Appelbaum, E., \& Batt R. (1994). The New American Workplace: Transforming Work Systems in the United States. Cornell ILR Press: Ithaca, NY.

Arthur, J.B. (1992). The link between business strategy and industrial relations systems in American steel minimills. Industrial and Labor Relations Review, 45, 488-506.

Arthur, J.B. (1994). Effects of human resource systems on manufacturing performance and turnover. Academy of Management Journal, 37: 670-687.

Ashkenas, R., Ulrich, D., Jick, T., \& Kerr, S. (1995). The Boundaryless Organization: Breaking the Chains of Organizational Structure. Jossey-Bass: San Francisco, CA.

Bailey, T. (1993). Discretionary Effort and the Organization of Work: Employee Participation and Work Reform since Hawthorn. Columbia University: New York, NY.

Barker, K. (1995). Contingent work: Research issues and the lens of morale exclusion. In L. E. Tetrick \& J. Barling (Eds.), Changing employment relations: Behavioral and social perspectives, 31-60. Washington DC: American Psychological Association.

Barney, J.B. (1991). Firm resources and sustained competitive advantage. Journal of Management, 17, 99-120.

Batt, R. (2002). Managing customer services: human resource practices, quit rates, and sales growth. Academy of Management Journal, 45, 587-597.

Becker, B., \& Gerhart, B. (1996). The impact of human resource management on organizational performance: Progress and prospects. Academy of Management Journal, 39, 779-801.

Bloom, M. (1999). The performance effects of pay dispersion on individuals and organizations. Academy of Management Journal, 42, 25-41.

Bloom, M., \& Michel, J.G. (2002). The relationships among organizational context, pay dispersion, 
and managerial turnover. Academy of Management Journal, 45, 33-42.

Boswell, W.R., \& Boudreau, J.W. (2001). How leading companies create, measure, and achieve strategic results through "line of sight". Management Decision, 39, 851-859.

Boswell, W.R. (in press). Aligning Employees with the Organization's Strategic Objectives: Out of 'Line of Sight," Out of Mind. International Journal of Human Resource Management.

Boudreau, J.W, \& Ramstad, P.M. (2003). Strategic I/O psychology and the role of utility analysis models. In Handbook of Psychology, Vol. 12, Borman W, Ilgen D, Klimoski R (eds). Wiley: New York, NY; 193-221.

Bretz, R.D., \& Judge, T.A. (1994). Person-organization fit and theory of work adjustment: Implications for satisfaction, tenure, and career success. Journal of Vocational Behavior, 44, 3254.

Bridges, W. (1995). Jobshift: How to Prosper in a Workplace without Jobs. Addison-Wesley: Reading, MA.

Cappelli, P. (1999). The New Deal at Work. Boston, MA: Harvard Business School Press.

Chatman, J.A. (1989). Improving interactional organizational research: A model of personorganization fit. Academy of Management Review, 14, 333-349.

Cohen, S.G., Mohrman, S.A., \& Mohrman, A.M. (1999). We can't get there unless we know were we are going: Direction setting for knowledge work teams. In Research on managing work teams, E. Mannix, \& M. Neale (eds). JAI Press: Greenwich, CT; 1-31.

Colvin, A.J.S, Batt, R., \& Katz, H.C. (2001). How high performance human resource practices and workforce unionization affect managerial compensation. Personnel Psychology, 54, 905-934.

Cowherd, D.M., \& Levine, D.I. (1992). Product quality and pay equity between lower-level employees and top management: An investigation of distributive justice theory. Administrative Science Quarterly, 37, 302-311. 
Delaney, J.T., \& Huselid, M.A. (1996). The impact of human resource management practices on perceptions of organizational performance. Academy of Management Journal, 39, 949-69.

Delery, \& Shaw, (2001). The strategic management of people in work organizations: Review, synthesis, and extension. Research in Personnel and Human Resource Management, 20, 165-197.

Dukerich, J.M., Golden, B.R., \& Shortell, S.M. (2002). Beauty is in the eye of the beholder: The impact of organizational identification, identity, and image on the cooperative behaviors of physicians. Administrative Science Quarterly, 47, 507-533.

Dunnette, M.D. (1973). Performance Equals Ability and What:: Center for the Study of Organizations: Oxford, England.

Dyer, L., \& Shafer, RA. (1998). From human resource strategy to organizational effectiveness: Lessons from research on organizational agility. In Research in personnel and human resource management, Suppl. 4, Wright PM, Dyer LD, Boudreau JW, Milkovich GT (eds). JAI Press: Greenwich, CT; 145-174..

Ehrenberg, R.G., \& Bognanno, M.L. (1990). The incentive effects of tournaments revisited: Evidence from the European PGA tour. Industrial and Labor Relations Review, 43, 74-S-88-S.

Eisenhart, K.M. (1989). Agency theory: An assessment and review. Academy of Management Review, 14, $57-75$.

Feldman, D.C., Doerpinghaus, H.I., \& Turnley, W.H. (1994). Managing temporary workers: A permanent HRM challenge. Organizational Dynamics, 23, 49-63.

George, J.M. (1992). The role of personality in organizational life: Issues and evidence. Journal of Management, 18, 185-213.

Gerhart, B., \& Milkovich, G.T. (1990). Organizational differences in managerial compensation and financial performance. Academy of Management Journal, 33, 663-691.

Gratton, L., Hope-Hailey, V., Stiles P., \& Truss, C. (1999). Linking individual performance to 
business strategy: The people process model. Human Resource Management, 38, 17-32.

Gupta, A., Govindarajan, V. (1984). Business unit strategy, managerial characteristics, and business unit effectiveness at strategy implementation. Academy of Management Journal, 27, 25-42.

Hackman, J.R., \& Oldham, G.R. (1976). Motivation through the design of work - test of a theory. Organizational Behavior and Human Performance, 16, 250.

Hackman, J.R, \& Oldham, G.R. (1980). Work Redesign. Addison-Wesley: Reading, MA.

Hoerr, J. (2001). We Can't Eat Prestige. Temple University Press: Philadelphia, PA.

Huselid M.A. (1995). The impact of human resource management practices on turnover, productivity, and corporate financial performance. Academy of Management Journal, 38, 635673.

Ichniowski, C., Kochan, T.A., Levine, D., Olson, C., \& Strauss, G. (1996). What works at work: Overview and assessment. Industrial Relations, 35, 299-333.

Jackson, S.E., Schuler, R.S., \& Rivero, J.C. (1989). Organizational characteristics as predictors of personnel practices. Personnel Psychology, 42, 727-786.

Janis, I.L. (1982). Groupthink (2 ${ }^{\text {nd }}$ edition). Houghton Mifflin: Boston, MA.

Jensen, M.C., \& Meckling, W.H. (1976). Theory of the firm: Managerial behavior, agency costs, and ownership structure. Journal of Financial Economics, 3, 305-360.

Karasek, R. (1989). Control in the workplace and its health-related aspects. In S. L. Sauter, J. J. Hurrell, Jr., \& C. L. Cooper (Eds.), Job control and worker health, 129-159. New York, NY: John Wiley \& Sons

Kerr, J.L., \& Jackofsky, E.F. (1989). Aligning managers with strategies: Management development versus selection. Strategic Management Journal, 10, 157-170.

Klein, K.J., Tosi, H., \& Canella, A.A. (1999). Multilevel theory building: Benefits, barriers, and new developments. Academy of Management Review, 24, 243-248. 
Kristof, A.L. (1996). Person-organization fit: An integrative review of its conceptualizations, measurement, and implications. Personnel Psychology, 49, 1-49.

Kristof-Brown, A.L., Zimmerman, R.D., \& Johnson, E.C. (2005). Consequences of individuals' fit at work: A meta-analysis of person-job, person-organization, person-group, and personsupervisor fit. Personnel Psychology, 58, 281-342.

Latham, G.P., \& Yukl, G.A. (1975). A review of research on the application of goal setting in organizations. Academy of Management Journal, 18, 824-846.

Lawler, E.E. III. (1994). From job-based to competency-based organizations. Journal of Organizational Behavior, 15, 3-15.

Lengnick-Hall, C.A., \& Wolff, J.A. (1998). Achieving consistency of purpose. Strategy \& Leadership, 26, 32-36.

Lepak, D.P., \& Snell, S.A. (1999). The human resource architecture: Toward a theory of human capital allocation and development. Academy of Management Review, 24, 31-48.

Lepak, D.P., \& Snell, S.A. (2002). Examining the human resource architecture: The relationships among human capital, employment, and human resource configuration. Journal of Management, $28,517-543$.

MacDuffie, J.P. (1995). Human resource bundles and manufacturing performance: Organizational logic and flexible production systems in the world auto industry. Industrial \& Labor Relations Review, 48(2), 197-221.

Matusik, S.F., \& Hill, C.W.L. (1998). The utilization of contingent work, knowledge creation, and competitive advantage. Academy of Management Review, 23, 680-697.

McCormick, E. (1976). Job and task analysis. In Handbook of Industrial and Organizational Psychology, Dunnette MD (ed). Rand McNally: Chicago, IL; 651-696.

Miles, R.E., \& Snow, C.C. (1978). Organizational Strategy, Structure and Process. McGraw-Hill: New 
York, NY.

Milkovich, G.T., \& Bloom, M. (1998). Rethinking international compensation. Compensation and Benefits Review, 30, 15-23.

Mintzberg, H. (1987). The strategy concept I: Five P’s for strategy. California Management Review, 30, $11-24$.

Nelson, J. (1997). The boundaryless organization: Implications for job analysis, recruitment, and selection. Human Resource Planning, 20, 39-49.

O’Connor, E.J., Pooyan, A., Weekley, J., Peters, L.H., Frank, B., \& Erenkrantz, B. (1984). Situational constraint effects on performance, affective reactions, and turnover: A field replication and extension. Journal of Applied Psychology, 69, 663-673.

Olian, J.D., \& Rynes, S.L. (1984). Organizational staffing: Integrating practice with strategy. Industrial Relations, 23, 170-184.

O’Neal, S. (1998). The phenomenon of total rewards. ACA Journal, 7, 6-16.

O’Reilly, C.A., \& Chatman, J. (1986). Organizational commitment and psychological attachment: The effects of compliance, identification, and internalization on prosocial behavior. Journal of Applied Psychology, 71, 492-499.

Peters, L.H., \& O’Connor, E.J. (1980). Situational constraints and work outcomes: The influences of a frequently overlooked construct. The Academy of Management Review, 5, 391-398.

Peters, L.H., O’Connor, E.J., \& Rudolf, C.J. (1980). Individual differences and job design reconsidered: Where do we go from here? The Academy of Management Review, 5, 249-255.

Pfeffer, J., \& Langton, N. (1993). The effect of wage dispersion on satisfaction, productivity, and working collaboratively: Evidence from college and university faculty. Administrative Science Quarterly, 38, 382-448.

Rousseau, D.M, \& Ho, V.T. (2000). Psychological contract issues in compensation. In Compensation 
in organizations: Current research and practice, Rynes SL, Gerhart B (eds). Jossey-Bass: San Francisco, CA ; 273-310.

Schuler, R.S., \& Jackson, S.E. (1987). Linking competitive strategies with human resource management practices. Academy of Management Executive, 1, 207-219.

Schneider, B. (1987). The people make the place. Personnel Psychology, 40, 437-454.

Schneider, B., Goldstein, H.W., \& Smith, D.B. (1995). The ASA framework: An update. Personnel Psychology, 48, 747-774

Simon, H.A. (1991). Organizations and markets. Journal of Economic Perspectives, 5, 25-44.

Tichy, N.M., Fombrun, C.J., \& Devanna, M.A. (1982). Strategic human resource management. Sloan Management Review, 23, 47-62.

Truss, C. (2001). Complexities and controversies in linking HRM with organizational outcomes. Journal of Management Studies, 38, 1121-1149.

Ulrich, D., \& Lake, D. (1991). Organizational capability: Creating competitive advantage. Academy of Management Executive, 5, 77-92.

Van Dyne, L., \& Ang, S. (1998). Organizational citizenship behavior of contingent workers in Singapore. Academy of Management Journal, 41, 692-703.

Vroom, V.H. (1964). Work and Motivation. J. Wiley: New York, NY.

Weick, K.E., \& Roberts, K.H. (1993). Collective mind in organizations: Heedful interrelating on. Administrative Science Quarterly, 38, 357-381.

Wright, P.M., \& Boswell, W.R. (2002). Desegregating HRM: A review and synthesis of micro and macro human resource management. Journal of Management, 28, 247-276.

Wright, P.M., \& McMahan, G.C. (1992). Theoretical perspectives for strategic human resource management, Journal of Management, 18, 295-320. 
Wright, P.M., Smart, D.L., \& McMahan, G.C. (1995). Matches between human resources and strategy among NCAA Basketball teams. Academy of Management Journal, 38, 1052-1075.

Wright, P.M., \& Snell, S.A. (1991). Toward an integrative view of strategic human resource management. Human Resource Management Review, 1, 203-225.

Wright, P.M., \& Snell, S.A. (1998). Toward a unifying framework for exploring fit and flexibility in human resource management. Academy of Management Review, 23(4), 756-772. 